\title{
Aid and the Supply Side: Public Investment, Export Performance, and Dutch Disease in Low-Income Countries
}

\author{
Christopher S. Adam and David L. Bevan
}

\begin{abstract}
Contemporary policy debates on the macroeconomics of aid often concentrate on short-run Dutch disease effects, ignoring the possible supply-side impact of aidfinanced public expenditure. In the simple model of aid and public expenditure presented here, public infrastructure generates an intertemporal productivity spillover, which may exhibit a sector-specific bias. The model also provides for a learning-by-doing externality, through which total factor productivity in the tradable sector is an increasing function of past export volumes. An extended computable version of this model is used to simulate the effect of a step increase in net aid flows. The simulations show that beyond the short run, when conventional demand-side Dutch disease effects are present, the relationship between enhanced aid flows and real exchange rates, output growth, and welfare is less straightforward than simple models of aid suggest. Public infrastructure investment that generates a productivity bias in favor of nontradable production delivers the largest aggregate return to aid, but at the cost of a deterioration in the income distribution. Income gains accrue predominantly to skilled and unskilled urban households, leaving the rural poor relatively worse off. Under plausible parameterizations of the model, the rural poor may also be worse off in absolute terms.
\end{abstract}

Recent global initiatives on debt relief and development assistance anticipate a significant increase in overall aid flows to the poorest countries and, at least in the medium term, a concentration of these flows on a small number of recipients (e.g., Commission for Africa 2005; United Nations Millennium Project

Christopher S. Adam is reader in development economics at the University of Oxford; his email address is christopher.adam@economics.ox.ac.uk. David L. Bevan is emeritus research fellow at St John's College in the University of Oxford; his email address is david.bevan@economics.ox.ac.uk. The article is based on work originally carried out for the World Bank and the U.K. Department for International Development (DFID-Uganda). The authors gratefully acknowledge the support of both institutions. They thank Tony Killick, Simon Maxwell, Catherine Pattillo, Luca Ricci, and seminar participants at the universities of Oxford, Western Ontario, Brunel, and Clermont-Ferrand. They also thank the Overseas Development Institute, and the International Monetary Fund for helpful comments. The article has also been much improved in response to comments by three anonymous referees and by the journal editor. Supplemental appendixes to this article are available at http://wber.oxfordjournals.org.

THE WORLD BANK ECONOMIC REVIEW, VOL. 20, NO. 2, pp. 261-290

doi:10.1093/wber/lhj011

Advance Access publication May 17, 2006

(C) The Author 2006. Published by Oxford University Press on behalf of the International Bank for Reconstruction and Development / THE WORLD BANK. All rights reserved. For permissions, please e-mail: journals.permissions@oxfordjournals.org. 
2005). Accompanying these pressures for a scaling-up of aid, however, is a heightened anxiety among some donors and potential recipients that large increases in aid may jeopardize macroeconomic stability and growth (Rajan and Subramanian 2005). Not surprisingly, these concerns are most acute in already aid-dependent countries, such as Tanzania and Uganda, whose recent track records on growth, policy reform, and poverty reduction mean they are best placed to take advantage of donors' willingness to increase aid but, arguably, where there might be most to lose if further aid increases were to undermine long-run growth.

In part, this anxiety reflects reservations about the absorptive and managerial capacity of overstretched public sectors to deliver higher public expenditure without a serious decline in quality, and in part it reflects deeper reservations about aid dependency and the impact of foreign aid on the domestic political economy (Adam and O'Connell 1999; Svensson 2000). However, more traditional concerns about the macroeconomics of aid also figure large, and these are the focus here.

Dominating these concerns is the fear that the Dutch disease effects of aid will inhibit development of the tradable goods sector and reduce growth in the recipient economy. Research has tended to focus on the tax-like distortion of aid or resource discoveries on the competitiveness of the tradable sector, typically where that sector enjoys learning-by-doing productivity effects (Van Wijnbergen 1984; Sachs and Warner 1995; Gylfason, Herbertsson, and Zoega 1997; Elbadawi 1999; Adam and O'Connell 2004). This conventional perspective may be overturned when productivity spillovers accrue in both tradables and nontradables. In this paper, the case is examined in which public infrastructure investment generates an intertemporal productivity spillover for both tradable and nontradable production, but in a potentially unbalanced manner. ${ }^{1}$ For example, public investment in rural roads is likely to affect the production of (nontradable) food crops more than urbanbased (tradable) manufactures, while the reverse is likely for, say, telecommunications infrastructure.

A second source of concern is that the distributional effects of higher public expenditure may run counter to inequality and poverty-reduction objectives. There are two elements here. The first is that the immediate beneficiaries of higher public investment expenditure tend to be the nonpoor working in the services and manufacturing sectors as opposed to the poor producing mainly food and cash crops. The second is that if public expenditure is devoted to infrastructure that enhances productivity in nontradable sectors, this may shift the domestic terms of trade against net producers of nontradables and, to the extent that the poor are located in these sectors,

1. That productivity externalities accruing to the production of nontradables might reverse conventional Dutch disease results is not new. Torvik (2001), for example, makes the same point, although he does not explore specific mechanisms through which these externalities may emerge. 
worsen the distribution of income. This is shown to be a distinct possibility in circumstances where preferences are nonhomothetic so that the income elasticity of demand for nontradable output (in this case basic food) is low. ${ }^{2}$

Section I outlines a simple two-sector, two-good model to highlight these Dutch disease effects in the presence of aid-financed public infrastructure investment and a learning-by-doing production externality. This model is highly stylized, and so section II presents a more detailed, calibrated simulation model, loosely based on data from Uganda, which permits examination of the magnitudes likely to prevail in reality as well as of the distributional pressures likely to arise under alternative aid-financed public expenditure strategies. Two core versions of the model are examined-with public infrastructure as the only dynamic externality and with this mechanism interacting with a learning-bydoing externality that captures the productivity spillovers associated with increased nontraditional export production-and subjected to sensitivity analysis. Both the core simulation results and the sensitivity analysis are discussed in section III.

The results suggest that for reasonable parameter values governing the supplyside response to public expenditure, traditional Dutch disease effects are not present beyond the short run and are likely to be dominated in the medium term by the positive supply-side effects of aid. Somewhat paradoxically, growth in aggregate exports and total output in the medium term are strongest when the productivity effects of public investment expenditure are skewed in favor of nontradable production, reflecting the aggregate dynamic gains arising from improvements in nontradable supply. These effects remain even if the country is assumed to be well endowed with public infrastructure and its productivity on the margin to be relatively low. Moreover, these results remain qualitatively unchanged in the presence of plausibly scaled learning-by-doing externalities in nontraditional exporting. The simulation model also highlights important distributional tensions that disadvantage rural households relative to urban households and that may even lead to an absolute decline in rural incomes.

\section{A Simple Model of Productivity Spillovers}

It is difficult and rather tedious to set out and give intuition to the characteristics of a full-scale simulation model. This section takes a shortcut by developing a simple stylized model that highlights the key features embedded in the full-scale simulation model employed in the remainder of the article. Think of this as a model of the model.

2. The implications of this combination are also explored by Matsuyama (1992) in his analysis of industrial takeoff, where the low-income elasticity of demand for agricultural output allows agricultural productivity growth to generate both the labor surplus and the declining price of the wage good (food) that fuel industrialization. 
Consider a two-period Ricardo-Viner small open economy in which the representative agent produces and consumes one nontraded good and one traded good. Private capital stocks are fixed and sector specific, and they do not depreciate, while a fixed endowment of labor, $L$, moves freely between sectors to equalize real consumption wages. The economy faces fixed external terms of trade, and there are no tariffs or taxes. Aid, represented by a fully fungible transfer of (tradable) resources, is the only international capital flow in the model. To focus on the mechanisms of interest, aid is received in the first period only, although in the simulation model applied in section II, aid flows are treated as permanent. Total aggregate expenditure consists of private expenditure on tradable and nontradable goods and public expenditure on infrastructure.

All values are expressed in terms of tradable goods, where $P_{\mathrm{T}}=1$. Hence, defining the real exchange rate as $P_{\mathrm{N}} / P_{\mathrm{T}}=Q$ and using superscripts $P$ and $G$ to denote private and government expenditure, the first-period income-expenditure balance is given by:

$$
E^{P}(Q, U)+E^{G}(Q, K)=R(Q ; L)+A
$$

where $U$ is the private utility, $K$ the public infrastructure capital, and $A$ is the aid. $E^{P}(Q, U), E^{G}(Q, K)$, and $R(Q ; L)$ represent the public expenditure function, private expenditure function, and the revenue function, respectively. Letting the supply and compensated demand functions for nontraded goods be $R_{Q}, E_{Q}^{P}$, and $E_{Q}^{G}$, respectively, first-period equilibrium in the nontraded goods market is given by:

$$
E_{Q}^{P}(Q, U)+E_{Q}^{G}(Q, K)=R_{Q}(Q ; L)
$$

Equations (1) and (2) imply that the trade balance is equal to the exogenous aid flow, thus, $E_{T}^{P}(Q, U)+E_{T}^{G}(Q, K)-R_{T}(Q ; L)=A$. Finally, the government budget constraint is defined as:

$$
E^{G}(Q, K)=A
$$

The government's role in this model is simply the conversion of donor aid into public infrastructure. Since infrastructure is composed of tradable and nontradable goods, the quantity of public investment actually realized will depend on the real exchange rate and the elasticity of substitution between tradable and nontradable goods in investment demand. ${ }^{3}$ Public investment takes place in the first period (at first-period prices) but augments productive capacity in either or both the tradable and nontradable sectors only in the second period. ${ }^{4}$

3. At this stage, no restrictions are imposed on this elasticity, although the simulation model in section II assumes a Leontief structure for public investment demand.

4. Notice that in this model, the first-period equilibrium embodies a latent externality, in the sense that the public capital stock is not optimized. Implicitly, the government is assumed to lack access to the tax or borrowing instruments required to raise $K$ sufficiently to exhaust the return from public capital. 
This completes the characterization of the first period. Two potential externalities come into play in the second period. First, firms in both the sectors may enjoy productivity gains from public infrastructure investment and, if forthcoming, these gains are sector specific but not appropriable by individual firms. Second, as noted in the introduction, an important strand in the debate about aid and Dutch disease has been the concern that aid-induced appreciations of the real exchange rate dilutes positive learning-by-doing externalities arising from tradable goods production. This is reflected by assuming that firms in the export sector benefit from learning-by-doing externalities, which, as with the effect of infrastructure, are not appropriable by individual firms. With second-period values denoted by lowercase letters, production in period 2 therefore depends on the real exchange rate, $q$, the size of the public capital stock, $K$, installed from period 1 , and the volume of first-period exports, $R_{T}$. Second-period GDP and sectoral equilibrium conditions are given by:

$$
\begin{gathered}
e(q, u)=r\left(q, K, R_{T}\right) \\
e_{q}(q, u)=r_{q}\left(q, K, R_{T}\right) \\
e_{t}(q, u)=r_{t}\left(q, K, R_{T}\right) .
\end{gathered}
$$

It is assumed that $r_{R}=q r_{q R}+r_{t R}>0$, where $r_{q R} \leq 0$ and $r_{t R}>0$. Spillovers therefore create their own biased shift in the production possibility frontier in the second period so that at fixed relative prices, the output of nontradables will fall in absolute terms (the Rybczynski theorem) in the face of higher first-period tradable production.

\section{First-Period Equilibrium}

Equations (1), (2), and (3) fully determine the first-period equilibrium. Total differentiation of these three equations produces the following expressions for the proportional change in the real exchange rate, private utility, and public infrastructure in terms of the increase in aid, where a "hat" denotes a proportional change (see supplemental appendix S.I, available at http://wber.oxfordjournals.org)

$$
\begin{aligned}
& \hat{Q}=\frac{1}{Q E_{Q}}\left[\frac{(\gamma / \phi) \Lambda^{G}}{B}\right] d A \\
& \hat{U}=\frac{1}{U E_{U}^{P}}\left[\frac{\eta(\gamma / \phi) \Lambda^{G}}{B}\right] d A
\end{aligned}
$$




$$
\hat{K}=\frac{1}{K E_{K}^{G}}\left[1-\frac{\eta(\gamma / \phi) \Lambda^{G}}{B}\right] d A
$$

where

$$
B=\Sigma_{Q Q}-\left[(1-\eta) \Delta_{Q Q}^{P}+\eta \Delta_{Q Q}^{G}\right]-\gamma\left[\frac{(1-\eta)}{(1-\phi)} \Lambda^{P}-\frac{\eta}{\phi} \Lambda^{G}\right]
$$

$E_{Q}$ is total (private plus government) demand for nontradables, and $\Sigma_{Q Q}>0$, $\Delta_{Q Q}^{P}<0$, and $\Delta_{Q Q}^{G}<0$ are the real exchange rate elasticities of supply and (private and government) demand for nontradables, respectively. The three parameters, $\phi, \gamma$, and $\eta$, describe the composition of government expenditure: $\phi$ is the share of government expenditure in total expenditure and $\gamma$ is the share of government expenditure on nontradables in total expenditure, so that $(\gamma / \phi)$ is the nontradable share in government expenditure and $\eta$ is its share in total demand for nontradables. Finally, $\Lambda^{P}$ and $\Lambda^{G}$ denote the (uncompensated) income elasticities of demand for nontradables of the public and private sectors.

Expressions (7) to (9) deliver the standard demand-side Dutch disease results. First, notice that unless $\Lambda^{P}$ is very large relative to $\Lambda^{G}$, $Q Q$, and $Q Q$, the expression for $B$ will be positive. Letting $\Delta_{Q Q}=(1-\eta) \Delta_{Q Q}^{P}+\eta \Delta_{O Q}^{G}$ be the overall real exchange rate elasticity of demand for nontradables, $B$ will be positive provided ${ }^{5}$

$$
\Lambda^{P}<\left(\frac{\eta}{1-\eta}\right)\left(\frac{1-\phi}{\phi}\right) \Lambda^{G}+\left(\frac{1-\phi}{\gamma(1-\eta)}\right)\left(\Sigma_{Q Q}-\Delta_{Q Q}\right) .
$$

Therefore, for reasonable values, an increase in aid will cause the real exchange rate to appreciate and will increase the first-period private welfare. The welfare result may at first seem counterintuitive, but the private sector is a net seller of the nontradable goods to the public sector so that the aid-induced real exchange rate appreciation generates a favorable movement in the privatepublic terms of trade. Finally, aid will increase public infrastructure as long as $B>\eta(\gamma / \phi) \Lambda^{G}$, which requires that

$$
\Lambda^{P}<\left(\frac{1-\phi}{\gamma(1-\eta)}\right)\left(\Sigma_{Q Q}-\Delta_{Q Q}\right)
$$

Assuming $\Lambda^{G}>0$, this is a stricter condition than that required for increased aid to cause the real exchange rate to appreciate and increase private welfare although, for the reasons stated in note 3 , this condition will be satisfied in most circumstances.

5. In the simulation model below, $\gamma \approx 0.10, \eta \approx 0.125$ and $\phi \approx 0.20$, so that the first term on the right side scales the sum of the real exchange rate demand and supply elasticities by a factor of about 9 . Since it is reasonable to expect that $\Lambda^{P}$ will be less than unity, then even if $\Lambda^{G}$ were very low $B$ would still be positive. 
In all three cases, the magnitude of these effects is determined by the structure of the economy. Consider, for example, the responsiveness of the real exchange rate to the aid inflow [equation (7)]. The tendency for the real exchange rate to appreciate moderates the higher are $\Sigma_{Q Q}, \Delta_{Q Q}^{P}$, and $\Delta_{Q Q}^{G}$ (in absolute value) but increases with the private and government income elasticities of demand for nontradables. ${ }^{6}$ A similar set of comparative static results can be derived for the private welfare and public expenditure effects of aid. Since these are not of central importance here, they are not discussed.

Notice that if there is no public investment response to the aid inflow [so that $E^{G}()=$.0 in equation (1) and aid resources accrue directly to the private sector as an income transfer], equation (3) disappears, yielding:

$$
\hat{U}=\frac{d A}{U E_{U}^{P}}
$$

and

$$
\hat{Q}=\frac{\Lambda^{P} d A}{E\left(\Sigma_{Q Q}-\Delta_{Q Q}^{P}\right)}
$$

which confirm the simple demand-side results of a pure consumption transfer, which emerge from any standard model (Devarajan, Lewis, and Robinson 1993). In this case, the aid flow is strictly welfare increasing and will unambiguously cause the real exchange rate to appreciate, with the extent of the appreciation being determined by the income elasticity of demand and the elasticities of demand and supply in the nontradable sector. ${ }^{7}$

\section{Second-Period Equilibrium}

The second-period equilibrium is derived in an analogous fashion by totally differentiating conditions (4) and (5) to solve for $d q$ and $d u$ in terms of $d K$, the productivity of investment in the two sectors, and $d R_{T}$, as follows. ${ }^{8}$ First, notice that from the properties of conditions (4), (5), and (6), the value of the marginal product of infrastructure capital is given by $r_{K}=q r_{q K}+r_{t K}$. Then, letting $\theta=q e_{q} / e$

6. In the case of the private-sector expenditure elasticity, the effect is unambiguous; in the case of the government elasticity, the responsiveness of the real exchange rate elasticity is increasing in $\Lambda^{G}$ provided condition (11) is satisfied.

7. Notice, also, that if public investment is entirely composed of tradables, so that $\gamma=\eta=\Lambda^{G}=0$, the obvious result is that $d Q / d A=d U / d A=0$ and $d K / d A=1 / E_{K}$, in other words the aid inflow has no consequences for the first-period real exchange rate or private utility and public capital increases in direct proportion to the aid inflow.

8. The results that follow are expressed in terms of $d K$, the increase in public infrastructure, rather than solving for $d K$ from expression (9) since from the second-period perspective, the relationship between the original aid flow and the volume of additional infrastructure it financed is immaterial. Though not done here, it would be a simple matter to solve the donor's optimal aid allocation as a function of the second-period productivity, given the donor's welfare function and budget constraint. 
be the share of nontradables in total expenditure, the following expressions are obtained for the changes in second-period utility:

$$
\hat{u}=\frac{1}{u e_{u}}\left[r_{K} d K+r_{R} d R_{T}\right]
$$

and in the second-period real exchange rate

$$
\hat{q}=\frac{\left[\left(\theta \lambda^{p}-1\right) q r_{q K}+\theta \lambda^{p} r_{t K}\right] d K+\left[\left(\theta \lambda^{p}-1\right) q r_{q R}+\theta \lambda^{p} r_{t R}\right] d R_{T}}{q e_{q}\left(\sigma_{q q}-\delta_{q q}\right)}
$$

where $\lambda^{p}$ is the second-period private-sector income elasticity of demand for nontradables, and $\sigma_{q q}>0$ and $\delta_{q q}<0$ are the second-period real exchange rate elasticities of supply and (private-sector) demand for nontradables, respectively. ${ }^{9}$

To interpret equations (15) and (16), consider first the case where there are no learning-by-doing effects $\left(r_{R}=r_{q R}=r_{t R}=0\right)$. Three key results may be noted. The first is that the change in second-period utility depends on the value of the aggregate product of public capital; it does not depend on the presence or absence of any bias in productivity. Second, and by contrast, the evolution of the real exchange depends on the scale of infrastructure investment and the relative bias in productivity spillover between the tradable and nontradable sectors. Thus, noting that $\left(\sigma_{q q}-\delta_{q q}>0\right)$, it follows that the higher the impact on nontradable productivity, the more likely is the real exchange rate to depreciate, and the higher the impact on tradable productivity, the more likely is the real exchange rate to appreciate. Third, these effects are moderated by the income elasticity of demand for nontradables. For given values of $r_{q K}$ and $r_{t K}$, the lower the income elasticity, $\lambda^{p}$, the weaker the tendency for the real exchange rate to appreciate. Specifically, solving equation (16), it follows that

$$
\hat{q}>0 \quad \text { as } \lambda^{p}>\frac{1}{\theta}\left[\frac{q r_{q K}}{q r_{q K}+r_{t K}}\right]
$$

and vice versa for $\hat{q}<0$. If productivity is exactly balanced, in the sense that $q r_{q k}=$ $r_{t k}$, condition (17) simplifies to:

$$
\hat{q}>0 \quad \text { as } \lambda^{p}>\frac{1}{2 \theta}
$$

9. Notice that the same result could be derived by solving equations (3) and (5). In this instance, equation (15) would take the form $\hat{q}=\left[\left((1-\theta) \lambda^{p t}-1\right) r_{t K}+(1-\theta) \lambda^{p t} q r_{q K}\right] d K+\left[\left((1-\theta) \lambda^{p t}-1\right) r_{t R}+\right.$ $\left.(1-\theta) \lambda^{p t} q r_{q R}\right] d R_{T} / e_{t}\left(\sigma_{t q}-\delta_{t q}\right)$, where $\lambda^{p t}$ is the second-period income elasticity of demand for tradables, and $\sigma_{t q}<0$ and $\sigma_{t q}>0$ are the second-period real exchange rate elasticities of supply and demand for tradables. 
The simulation model in section II considers only extreme-bias cases where alternately $q r_{q K}=0$ and $r_{t K}=0$. In the first case, where productivity gains are located exclusively in the tradable sector, the real exchange rate will unambiguously appreciate for any non-negative income elasticity, while in the second case, where productivity gains are located exclusively in the nontradable sectors, condition (17) becomes:

$$
\hat{q}>0 \quad \text { as } \lambda^{p}>\frac{1}{\theta} \text {. }
$$

These three results highlight the principal aggregate effects of aid that are explored in the remainder of the article. They indicate that, other things equal, in the presence of productivity effects, the evolution of the equilibrium real exchange rate is, in general, ambiguous. However, where aid-financed public expenditure is targeted at improving the productivity of the nontradable sector and where income elasticities of demand for nontradable goods such as basic food are low, the initial appreciation is likely to be followed by a subsequent equilibrium depreciation of the real exchange rate.

Consider, next, the effect of introducing the learning-by-doing spillover. In the natural case where $r_{q R}=0$ (learning by doing does not affect the productivity of the nontradable sector), it follows that with $r_{t R}>0$, an aid inflow that lowers the first-period net exports (so that $d R_{T}<0$ ) will lower the second-period welfare relative to equation (15) and will lead to a more appreciated real exchange rate (and hence a lower level of net exports) relative to equation (16). This effect is larger, other things equal, the higher is the income elasticity of demand for nontradables and the larger is the share of nontradables in total expenditure. Whether this second externality could reverse the sign of $\hat{u}$ or $\hat{q}$ will, of course, depend on the relative size of the two externalities and the changes triggering them $\left(d K\right.$ and $\left.d R_{T}\right)$. As is shown in section III, the positive effects flowing from public infrastructure investment dominate the negative learning-by-doing effects for reasonable calibrations of the simulation model, which is described in the next section.

\section{The Simulation Model}

The analytical model is necessarily highly stylized. It assumes fixed private resource endowments and a highly simplified government structure, and it focuses only on aggregate production and consumption. The simulation model presented here provides a sense of the magnitude of the possible effects policymakers are likely to confront and unpacks some of the firstorder distributional consequences of the aid and public expenditure interaction. This is a recursively dynamic real computable general equilibrium model of a small open economy calibrated to reflect the principal features 
of an archetypical low-income aid-dependent economy. ${ }^{10}$ The equations of the model, along with the calibration data, are detailed in the supplemental appendix.

\section{Private Production and Consumption}

Producers and consumers are assumed to enjoy no market power in world markets, so the terms of trade are independent of domestic policy choices and are, for convenience, held constant across all simulations. Firms in each of the four sectors (food crop agriculture, cash crops, manufacturing, and services) are assumed to be perfectly competitive, producing a single good that can be sold to either the domestic or the export market. Production in each sector $i$ is determined by a Cobb-Douglas function of the form

$$
X_{i}=A_{i} S_{i}^{\alpha s} L_{i}^{\alpha l} \mathrm{KP}_{i}^{\alpha k} \mathrm{KG}^{\alpha g}
$$

where $S$ is land, KP is sector-specific private capital, $K G$ is infrastructure, and $L$ is a composite labor input. Only production in the rural sectors requires land, which is fixed in perpetuity. Private-sector-specific capital stocks are fixed in each period but evolve over time through depreciation and gross investment. The labor composite, $L$, is constructed as a constant elasticity of substitution aggregation of skilled and unskilled labor, with fixed supplies that are intersectorally mobile. Labor markets are competitive so that composite labor is employed in each sector up to the point that it is paid the value of its marginal product. Private-sector output is also determined by the level of infrastructure, KG, which is provided by the government. Constant returns to scale prevail in the private factors of production, but increasing returns are possible in the presence of public infrastructure.

The distributional consequences of aid and public expenditure are tracked through their impact on three household types differentiated by factor ownership and patterns of consumption and saving. The first is a rural household, which is involved in food crop and cash crop agriculture and owns the land and capital in these two sectors. This household is outside the direct tax net and has zero net savings. ${ }^{11}$ The second is an urban unskilled household, whose only factor of production is unskilled labor, which it supplies to the manufacturing, services, and government sectors. It owns no capital or land and has zero gross and net savings but, in contrast to the rural household, it pays direct taxes. Finally, the urban skilled household supplies skilled labor to the manufacturing, services, and public sectors and owns the remainder of the capital in the economy. This household pays direct taxes to government at a higher rate than the

10. The underlying social accounting matrix is loosely based on data from Uganda around the turn of the century but offers a reasonable representation of many similar cash crop agriculture-based economies.

11. The rural household's gross savings are constrained to be equal to the depreciation of agricultural capital. 
unskilled household, earns interest on its net holdings of government domestic debt, and has positive net savings in the initial equilibrium.

Consumption for each household type is defined by a constant elasticity of substitution linear expenditure system, which allows for the income elasticity of demand for different goods to deviate from unity. In the simulations reported in the next section, attention is restricted to the case where only food consumption is subject to a subsistence threshold. This implies that the marginal income elasticity of demand is less than unity for food and greater than unity for all other goods (manufactured goods and services). ${ }^{12}$

\section{Macroeconomic Closure and Dynamics}

The default is a neoclassical closure in which total private investment is constrained by total savings net of exogenous public investment, where household savings propensities are exogenous. This rule, broadly consistent with conditions in the poorest countries where unrationed access to world capital markets is virtually zero and domestic private saving is relatively interest inelastic, means that the shortfall of government savings relative to the cost of government capital formation, net of exogenous foreign savings, directly crowds out private investment (and the excess of government savings directly crowds in private investment).

There is a risk, however, that this closure rule exaggerates the private investment response to public investment (either positively or negatively). Therefore, the simulation experiments are also run under an alternative closure that defines an independent, return-sensitive, private aggregate investment function and that allows for the marginal savings propensity of the urban skilled household to adjust endogenously. As discussed in more detail in the next section, the key insights delivered by the simulation model are not greatly altered by the choice of closure rule, but for completeness simulations for the alternative Kaldorian closure rule are reported in the supplemental appendix S.III available online.

The model has a simple recursively dynamic structure. Each solution run tracks the economy over 10 periods from the initial policy change, and each period may be thought of as a fiscal year. Within-year public and private capital stocks are fixed, and the model is solved given the parameters of the experiment (e.g., the change in aid flows and the corresponding public expenditure response). This solution defines a new vector of prices and quantities for the economy, including the level of public- and private-sector investment, which feed into the equations of motion for sectoral capital stocks:

$$
K_{i, t}=K_{i, t-1}\left(1-\mu_{i}\right)+\Delta K_{i, t-j}
$$

12. Since cash crops are produced solely for export, final household consumption is defined over food, manufactures, and services only. 
where $K_{i}=\left\{\mathrm{KP}_{i}, \mathrm{KG}\right\}, \mu_{i}$ denotes the sector-specific rate of depreciation, and $j$ measures the gestation lag on investment. In the simulations presented below, the default setting is $j=1$, although the effects of assuming that public investment augments the stock of infrastructure capital only with a longer lag are also examined. To focus exclusively on the impact of increased aid flows on the economy, the model is calibrated to an initial static steady-state equilibrium in which net public and private investment is zero (gross investment exactly matches depreciation), and there is no growth in the labor supply.

The final element is the learning-by-doing externality. Learning by doing is assumed to generate a Hicks-neutral innovation to total factor productivity in the manufacturing sector (the nontraditional export sector). Specifically, equation (20) assumes that $A_{i t}=A_{i}$ for nonspillover sectors, while in the spillover sector, denoted $s$, total factor productivity evolves according to

$$
A_{s t}=A_{s 0}\left[1+\psi\left(\ln E_{t}^{p}-\ln \bar{E}_{t}^{p}\right)\right]
$$

where $E_{t}^{p}=\sum_{j=1}^{\infty} \beta^{j} E_{t-j}$ is the (discounted) sum of exports in the spillover sector up to and including $t-1$ under the simulation experiment, and $\bar{E}_{t}^{p}$ is the correspondingly defined cumulative exports under the baseline trajectory for the economy. The term $\psi \geq 0$ measures the extent of the spillover, $\beta=(1+\rho)^{-1}<$ 1 is the discount factor, and $A_{s 0}$ is the value of $A_{s t}$ in the baseline calibration. Hence, the higher the $\rho$, the lower is the impact of experience on current productivity, but for any $\rho<\infty$, there will always be some persistence in $\left(\ln E_{t}^{p}-\ln \bar{E}_{t}^{p}\right)$ so that temporary policy reforms will have at least some permanent consequence for productivity.

\section{Aid and Government Expenditure}

To focus on the principal mechanisms of interest, aid is assumed to accrue to government and is used exclusively to finance increased public investment expenditure. ${ }^{13}$ Two further assumptions are made.

The first is that an increased public capital stock entails a higher level of operations and maintenance (O\&M) expenditure. This is calibrated on the basis of evidence on the recurrent expenditure requirements of World Bankfinanced capital projects compiled by Hood, Husband, and Fu (2002). Recurrent O\&M is set to 3.5 percent of the additional capital stock (the Hood, Husband, and Fu weighted average across all projects). A higher O\&M rate is also considered corresponding to Hood, Husband, and Fu's highest estimated rate of 7.5 percent (for education). The baseline assumption is that these additional O\&M costs are financed out of the additional aid flow so that the

13. Hence, there is no examination of the consequences of changes to the structure of taxation, the level of reserves, or the volume of real recurrent expenditure (other than those arising directly from public investment, such as operations and maintenance; see below), all of which are kept constant across all simulations. 
domestic budget deficit is (ex ante) unchanged. In the sensitivity analysis reported in the supplemental appendix S.III, the case is also examined in which aid flows finance only the installation of public capital, and O\&M expenditures are met through increases in the domestic budget deficit. ${ }^{14}$ In both cases, it is assumed that the government takes into account price changes in determining the volume of expenditure that can be financed with the additional aid. Second-order changes to household incomes, demand, and relative prices arising from inframarginal government activities are not, however, internalized in the government's decisions, so the experiments are not necessarily budget neutral ex post, even when O\&M costs are aid financed.

The second assumption concerns the nature of public investment expenditure. In keeping with much of the evidence on Poverty Reduction Strategy Papers, the baseline simulations assume that aid-financed increases in public investment expenditure are more intensive in nontradable inputs on the margin than for both private investments and inframarginal government expenditure. Scaling-up is therefore assumed to skew aggregate demand toward nontradables in the short run. The sensitivity analysis considers two key variations, however. One allows for the possibility that public investment demand is less nontradable intensive than average (which may be the case when government infrastructure investment is geared toward, say, upgrading telecommunications technologies or employing more technical assistance). The other is that an aid-financed scaling-up of public investment entails additional demand for labor, beyond that entailed by O\&M requirements reflecting, for example, greater management and coordination burdens placed on the public sector.

Finally, although it is reasonable in practice to assume that public investment in areas such as health and education will augment human capital and thereby generate a source of extensive productivity growth, these effects are not included in the simulations. This feedback is relatively slow, and the simulations reflect a medium term in which adjustment to the physical capital stock takes place but where changes to the human capital stock have not yet materialized. ${ }^{15}$

\section{EXPERIMENTS AND Results}

This section describes the simulation experiments and discusses the core simulation results and the sensitivity results.

14. There are of course other ways in which this issue could be handled. The first is through matching increases in domestic taxes, and the second is to set the level of O\&M as a choice variable, with the rate of effective depreciation of the public capital stock being a (negative) function of the level of O\&M expenditure. In this case, failing to meet O\&M requirements serves to accelerate the rate of depreciation of public infrastructure.

15. The model by Agénor, Bayraktar, and Aynaoui (2005), by contrast, provides an explicit treatment of the links between public investment and human capital formation. 


\section{Simulation Experiments}

The policy experiment consists of an increase in public infrastructure investment financed by a permanent 12.5 percent increase in the net (grant) aid inflow to the economy. This increase is equivalent to just under 2 percent of baseline GDP, a step increase roughly equivalent to the size of the increase in net aid flows to Mozambique, Tanzania, and Uganda at the end of the last century related to the Heavily Indebted Poor Countries Debt Initiative. In all cases, the additional aid flow is used exclusively to finance an increase in public infrastructure investment, holding tax rates and all other components of public expenditure (with the exception of O\&M expenditure) constant. Consequent changes in the domestic budget balance after grants therefore reflect general equilibrium effects arising from the increased public spending and are accommodated through adjustments to private saving or investment, depending on the macroeconomic closure rule.

Table 1 summarizes the core simulations and a set of variations around these. The potential simulation space is vast: in principle, each core simulation can be implemented under any of the variants and many combinations of the variants.

\section{TABle 1. Simulation Experiments}

\begin{tabular}{cl}
\hline Experiment & \multicolumn{1}{c}{ Description } \\
\hline Core simulations & No productivity spillovers from infrastructure capital \\
1 & Neutral productivity spillovers \\
2 & Export-biased productivity spillovers \\
3 & Domestic-biased productivity spillovers \\
4 & As 4, with subsistence threshold for food \\
5 & \\
Variants & Learning-by-doing spillover $=0.20$ \\
$\mathrm{a}$ & Learning-by-doing spillover $=0.45$ \\
$\mathrm{~b}$ & Learning-by-doing spillover $=0.00$ with three-year gestation \\
$\mathrm{c}$ & lag on public investment \\
& Learning-by-doing spillover $=0.20$ with three-year gestation \\
$\mathrm{d}$ & lag on public investment \\
& Elasticity of substitution between skilled and unskilled labor $=0.50$ \\
$\mathrm{e}^{\mathrm{a}}$ & Elasticity of substitution between skilled and unskilled labor $=2.00$ \\
$\mathrm{f}^{\mathrm{a}}$ & Public investment demand is tradable-good intensive \\
$\mathrm{g}^{\mathrm{a}}$ & High initial public capital $(\mathrm{KG}=75 \%$ of optimal value and \\
$\mathrm{h}^{\mathrm{a}}$ & spillover $=0.25)$ \\
& Operations and maintenance $(\mathrm{O} \& \mathrm{M})=0.0 \%$ \\
$\mathrm{i}^{\mathrm{a}}$ & O\&M $=7.5 \%$ \\
$\mathrm{j}^{\mathrm{a}}$ & O\&M $=3.5 \%$ plus additional public-sector labor demand \\
$\mathrm{k}^{\mathrm{a}}$ & O\&M = 3.5\% financed through higher domestic budget deficit \\
$\mathrm{l}^{\mathrm{a}}$ & As 1 with additional public-sector labor demand \\
$\mathrm{m}^{\mathrm{a}}$ & Kaldorian closure \\
$\mathrm{n}^{\mathrm{a}}$ & As m with Kaldorian closure \\
$\mathrm{o}^{\mathrm{a}}$ & \\
\hline
\end{tabular}

${ }^{a}$ Reported in supplemental appendix, available at http://wber.oxfordjournals.org. 
Only a small number of simulations illustrating the key features of the results are presented here; the sensitivity analysis offers some support to their robustness.

The core simulations are presented in table 2 . Simulation 1 is the benchmark. The infrastructure investment has no effect on private-sector productivity: the economy's total capital stock is increased, but the increased public capital does not sustain higher private output. This allows the pure demand-side effects of the aid flow to be isolated.

Simulation 2 examines the case where the infrastructure investment enhances private-sector productivity, but the effects are uniform across all sectors of the economy and are represented by a balanced outward shift in each sector's production possibility frontier between domestic (nontradable) and export (tradable) variants of the good.

The remaining permutations on the basic experiment (simulations 3-5) examine three central cases in which the productivity impact is still felt across all sectors but now embodies a bias such that within each sector the shift in the production possibility frontier is skewed in favor of either export- or domesticgood production. Specifically, only the "extreme-bias" cases described in equations (17) and (20) are considered, represented by a rotation in the frontier around either end point. Simulation 3 considers the case of an export bias in the productivity effects of government infrastructure, and simulations 4 and 5 a domestic-good bias. Simulations 1-4 assume that the subsistence component in consumption is zero so that the consumption is homothetic in income across all goods and households. In simulation 5, however, a subsistence component is imposed for food consumption so that the income elasticity of demand for food falls below one.

These runs are all based on a common set of assumptions, which are varied in subsequent simulations to assess the robustness of the central findings. The core assumptions and principal variations (reported in table 1) are explained below, where each variation can be applied to any or all of the core simulations.

First, to reflect the idea that there is often a severe shortage of (functional) infrastructure capital in countries to which this model applies, public infrastructure capital stock is assumed at only half its "optimal" value. ${ }^{16}$

Second, there is very little empirical consensus on the size of the productivity effects of infrastructure investment in low-income countries. The assumed value for this parameter is $a_{\mathrm{G}}=0.50$, comparatively higher than the values estimated in Hulten's (1996) study of infrastructure capital and economic growth. This higher baseline value reflects in part the expectation of a higher marginal product of public capital for countries with a severely depleted capital stock

16. The optimal public capital stock is defined as the amount at which the marginal product of public capital is equal to the average marginal product of private capital, given the initial endowments of private factors (land, labor, and capital) and the assumed parameters of the production function. At such a point, the output gain from a tax- or deficit-financed increase in infrastructure capital would exactly offset the loss arising from the crowded-out private capital. 


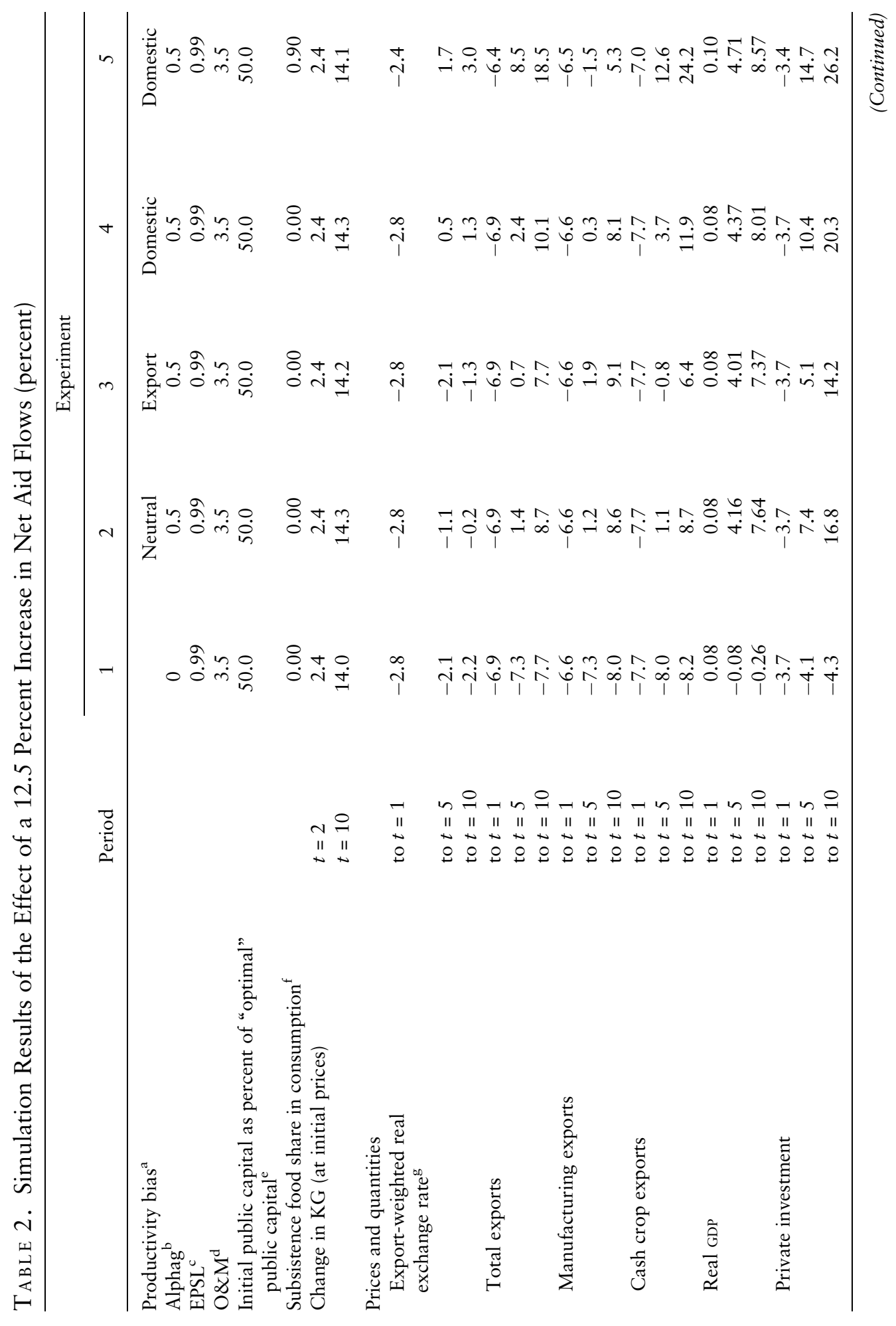




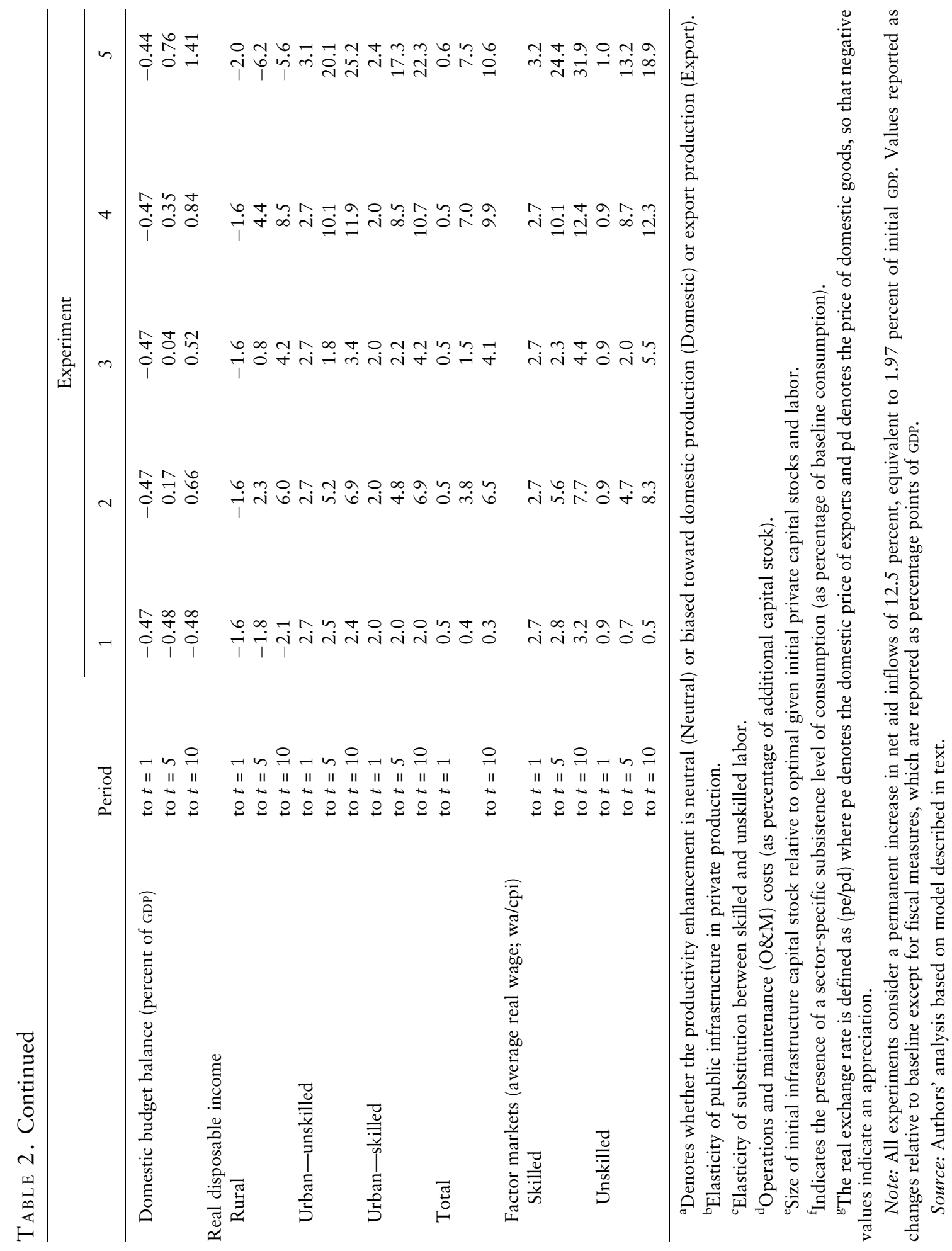


and in part the likelihood that the contemporary marginal productivity of public infrastructure expenditure may in fact be higher than the historical point estimates suggest. Both the size of the initial public capital stock and its productivity are exogenous parameters of the model, and both could be either high or low. The sensitivity analysis reported in the supplemental appendix S.III examines the robustness of the core results to the case where the economy is endowed with a larger infrastructure capital stock and a lower return on the margin (denoted as variant "h"). ${ }^{17}$

Third, scaling-up is assumed to entail additional O\&M expenditure equivalent to 3.5 percent of the increase in the public capital stock, with this additional expenditure met from aid inflow. The sensitivity analysis allows for lower and higher values of the O\&M rate, for additional public labor demand in support of scaling-up, and for an alternative mechanism for financing this additional expenditure. These possibilities are reflected in variants "i" to " $\mathrm{m}$."

Fourth, it is initially assumed that there are no dynamic externalities to exporting. The evidence base for the learning-by-doing spillover is far from conclusive, and the sensitivity analysis experiments with plausible alternative values. The central value for the elasticity of total factor productivity in the manufacturing sector with respect to nontraditional exports [the parameter in equation (22)] is set to $\psi=0.20$. Since this value is highly contested, a value of $\psi=0.45$ is also considered. These possibilities are reflected in variants $\mathrm{a}$ and $\mathrm{b}$.

Fifth, the initial simulations set the elasticity of substitution between skilled and unskilled labor to unity [so that equation (20) becomes Cobb-Douglas in all factors]. This assumption is then relaxed by examining the cases where the elasticity of substitution is low $\left(\sigma_{L}=0.50\right)$ and where it is high $\left(\sigma_{L}=2.00\right)$. These possibilities are reflected in variants $e$ and $f$.

Lastly, infrastructure investment is initially assumed to augment the capital stock with a lag of one year. The sensitivity analysis considers the case where public infrastructure investment has a longer gestation, taking three years to augment private productivity. These possibilities are reflected in variants $\mathrm{c}$ and $\mathrm{d}$.

For each experiment, the impact effect (year 1) and the cumulative evolution of the economy after 5 and 10 years are reported. To simplify the presentation, the focus is on changes in only a small number of key aggregates: the exportweighted real exchange rate, the volume and composition of exports, real GDP, private investment, the fiscal balance, and the real disposable income of the three household types, measured in terms of the household-specific consumption price index. For a given level of government expenditure, real disposable income is a direct measure of household welfare. Figures 1-4 also report the evolution of the real exchange rate, total exports, total real disposable income, and the rural household's share in this.

17. The sensitivity analysis not reported here suggests that the variation in the behavior of the economy between these points is fairly regular. 
Figure 1. Export-Weighted Real Exchange Rate Response to Aid-Financed Public Investment

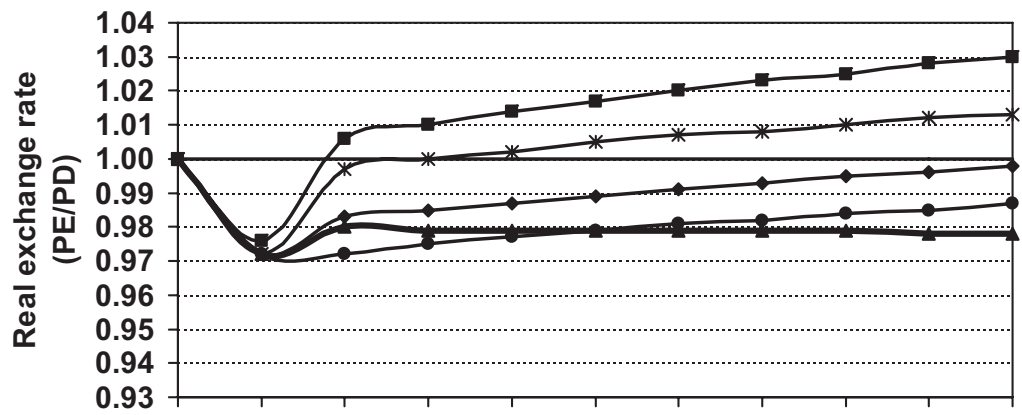

20012002200320042005200620072008200920102011

Simulation period

$\rightarrow$ Base case
$\rightarrow$ Neutral
$\rightarrow$ Export bias
- Domestic bias
$\rightarrow$-Domestic bias: linear expenditure system

Figure 2. Total Export Response to Aid-Financed Public Investment
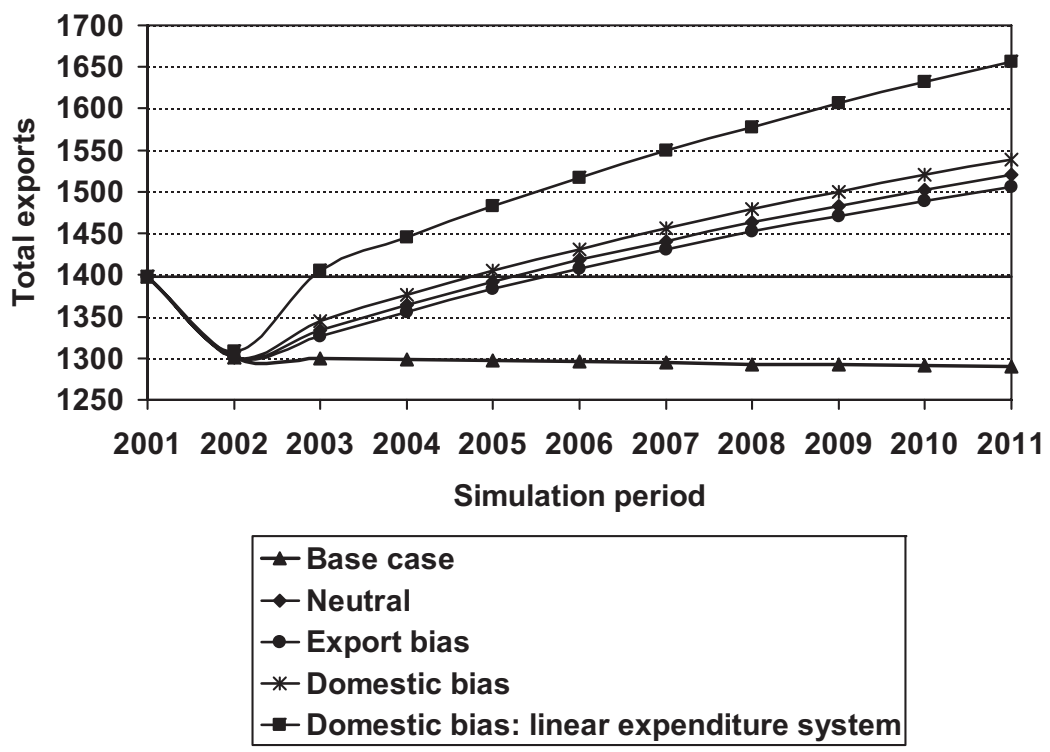
Figure 3. Real Household Disposable Incomes in Response to Aid-Financed Public Investment

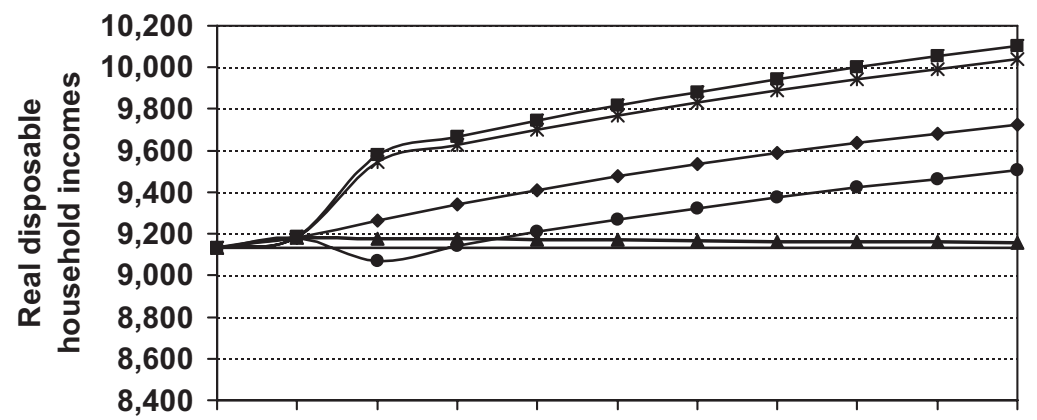

20012002200320042005200620072008200920102011

Simulation period

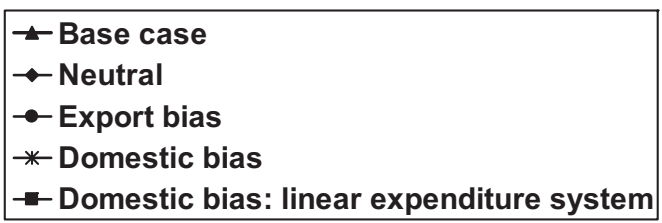

Figure 4. Rural Share in Total Income in Response to Aid-Financed Public Investment
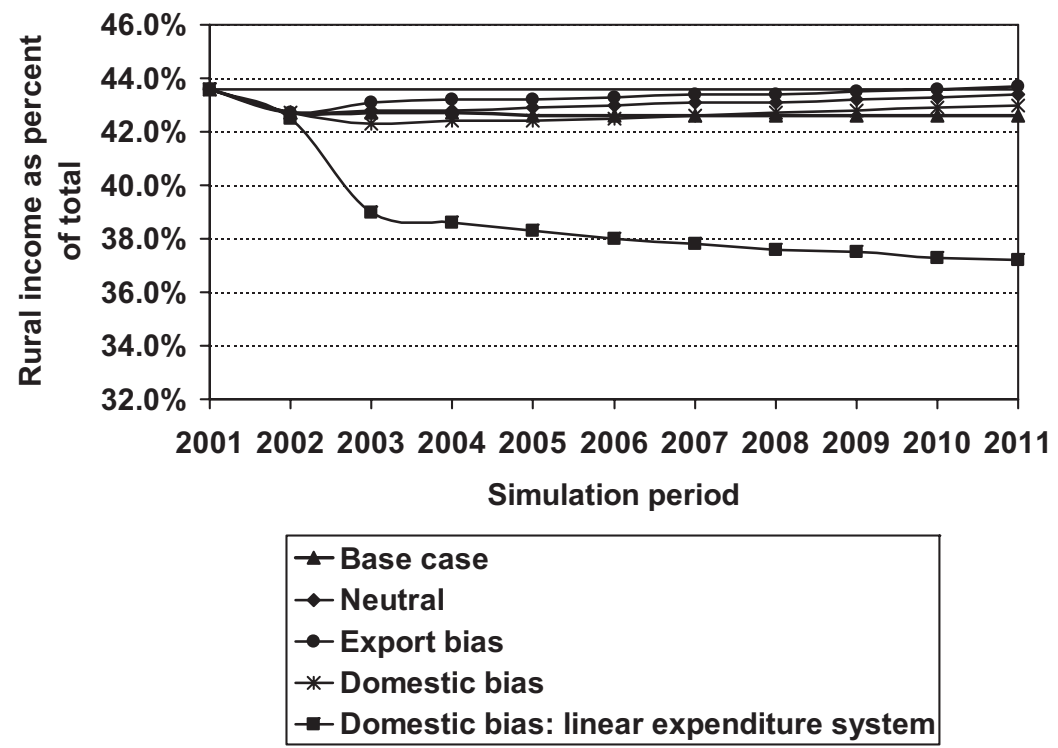


\section{Results}

UnProductive InFRASTRUCTURE. Experiment 1 provides a benchmark. Here, the infrastructure investment confers no benefits on private productivity so that in terms of the model in section I, $q r_{q K}=r_{t K}=0$. Hence, the aid flow has little initial impact on GDP, but it does lead to an appreciation of the export real exchange rate and a sizable contraction in exports in favor of higher production of domestic goods.

In contrast to the endowment model of section I, the evolution of the simulated economy over the medium term points to a progressive deterioration in overall economic performance because of the decline in real private-sector investment. This reflects both a decline in total savings as the fiscal balance deteriorates, in turn a reflection of the adverse effects of the real exchange rate on the budget, ${ }^{18}$ and the effect of the real exchange rate appreciation on the cost of capital goods (since capital formation is intensive in nontradable services). This means that although the appreciation of the real exchange rate moderates over time, the deterioration of the capital stock ensures that the decline in export performance does not reverse and hence that initial welfare gains weaken over time.

Finally, while total real income increases, rural households actually suffer a decline in income, both absolutely and relative to urban households. The principal reason is that the demand effects from increased government expenditure fall disproportionately on urban skilled and unskilled labor and on intermediate goods from the manufacturing and services sectors. Backward linkages from the formal urban sectors (manufacturing, services, and government) to the rural sectors (food and cash crops) are extremely weak. As later results show, these demand effects may be largely offset when the aid inflow is used productively but may re-emerge and be exacerbated when relative price effects turn against the rural sector and the income elasticity of demand for food is low.

Productive Infrastructure. By contrast, in experiments 2-5, government infrastructure investment raises private-sector productivity. In experiment 2, this productivity effect is uniform across sectors and between production for domestic and export markets. There is now fairly substantial cumulative growth in GDP over the 10 years, some improvement in the fiscal balance, and a marked increase in private investment. ${ }^{19}$ As a consequence, while the impact effects on the real exchange rate and on exports are identical to those in experiment 1 , because of the time lag before the productivity effects kick in, the impacts diverge sharply over time. Virtually all of the real exchange rate appreciation

18. Since government in this model is a net seller of foreign exchange, the real exchange rate appreciation reduces the domestic value of the budget balance and therefore increases the domestic financing requirement.

19. Government revenue grows as real incomes and expenditures grow while, after the initial step change, real government spending does not. Savings available for private investment grow partly with GDP but also because of crowding-in from the improvement in the fiscal balance. It is a consequence of the closure rule mentioned earlier that these resources are duly invested. 
has been unwound by the end of the 10-year period. Moreover, even though the real exchange rate remains somewhat appreciated relative to its baseline value, the initial 6.9 percent fall in export volumes is reversed, moving to an 8.7 percent increase over the baseline by the end of the simulation.

While the impact effects on household incomes are the same as in the previous experiment, so that rural income again initially falls, matters now improve over time. Not only is total real income 6.5 percent higher over the long run, but rural households enjoy a similar increase in real income over time in this experiment, even though their proportionate gain is slightly lower than that of urban households.

Experiments 3 and 4 consider the outcome if the productivity gains witnessed in experiment 2 are biased toward the production of either tradable (exportable) or nontradable (domestic) goods. In the case of experiment 3 , while the productivity effect is again positive and uniform across sectors, it is now biased within the food and manufacturing sectors in favor of export production. As expected, when there is no increase in the productivity of nontradable production, this leads to a more appreciated path for the real exchange rate than in the neutral experiment 2 . Hence, although manufacturing export performance is stronger because of the productivity bias, traditional cash crop exports are hit relatively hard, some 2.3 percentage points lower than when productivity gains are neutral.

When the productivity gain is biased entirely toward production of the domestic good, as in experiment 4 , outcomes are markedly different. The bias in production (which increases the supply of nontradable goods) is sufficiently strong to more than offset the demand effects of the increased aid flows so that the initial real exchange rate appreciation is reversed within five years. ${ }^{20}$ The effects on exports are symmetrical with those in experiment 3; cash crop exports recover more strongly than in earlier experiments, but the domestic bias in manufacturing productivity results in a more sluggish recovery in manufacturing exports. Overall export performance is stronger with a domestic bias than with an export bias, reflecting the real depreciation induced by the domestic bias.

The domestic-biased supply response also leads to a larger improvement in the long-run fiscal balance (of 0.8 percentage points of GDP), reflecting favorable relative price movements (see note 19) as well as the effects of higher growth and investment than in either the neutral or export-biased forms of productivity growth.

The most striking difference between these two experiments, though, is the effect on real household disposable incomes. Compared with the case of a neutral supply response, a strong export bias in the productivity gain induced by infrastructure expenditure sharply moderates real income growth in the economy. Long-run total income rises only 4.1 percent over its baseline compared with 6.5 percent when the supply response is neutral between export and domestic production. However, the income gain is spread somewhat differently

20. The model in section I predicts that the real exchange rate change should be exactly zero. That it is not so in the simulation model reflects its richer structure, including the fact that the government budget is not invariant to changes in the real exchange rate. 
across household groups, with urban unskilled workers now doing less well than the other two groups. This contrasts sharply with the domestic-biased supply response, which generates a markedly higher aggregate real income gain of 9.9 percent in the long run but one that is disproportionately skewed in favor of urban households.

As noted above, demand-side effects imply a tendency for urban households to gain disproportionately from aid-financed increases in infrastructure because of low backward linkages from government expenditure to the rural sector of the economy. The relative price movements underpinning experiment 4 exacerbate these weak linkages. As the economy's increased ability to produce domestic goods reverses the real exchange rate appreciation, this shifts the domestic terms of trade in favor of those consuming the now relatively cheaper domestic goods (all households) and against those producing them (the rural household). Rural households thus share more or less equally in the consumption gain from lower cost domestic goods but share disproportionately in the income loss from producing them.

In experiments 2 and 4, these adverse distributional effects are weak enough that they only partially offset rural households' share in the aggregate income gain for the economy. This is not the case, however, in experiment 5 . This experiment repeats the previous one but assumes a high subsistence requirement in food consumption for all households. The implication is that, once households have met this requirement, positive income gains will be allocated disproportionately away from food expenditure so that on the margin the income elasticity of demand for food will be less than unity-increasingly so the higher is the subsistence threshold and vice versa for the other sectors. The effect of this adjustment to assumed consumer behavior is dramatic. After its impact appreciation, the real exchange rate depreciates sharply and becomes more depreciated over time. Similarly, export volumes increase substantially after their initial fall, as do the fiscal balance, private investment, and real GDP. In all cases, the gains are greater than in any of the other experiments. The same holds for aggregate real income, which increases by 10.6 percent over the baseline in the long run.

The distributional impact in this experiment is rather unpleasant, though. Urban households enjoy substantial real income gains because of the decline in food prices, while rural households experience large income falls. The reason is simple: the adverse shift in the internal terms of trade against rural households noted in experiment 4 is magnified by the low-income elasticity of demand in food consumption from all households. As net producers, rural households suffer twice over: the fall in food prices caused by the increase in supply is exacerbated by the weakness in the demand for food because of the low-income elasticity. ${ }^{21}$

21. The size of these effects clearly reflects the subsistence threshold; the lower the subsistence food share in private consumption, the larger the local income elasticity of food and the smaller the quantitative difference between experiment 5 and experiment 4. Although the effects are not everywhere proportional, reducing the subsistence share in food consumption from 90 to 45 percent produces a simulated outcome that lies roughly mid-way between experiments 4 and 5 regardless of which variants are examined. 


\section{Learning by Doing and Gestation Lags}

Table 3 introduces two factors that might be expected to modify the results presented in table 2 .

First, a learning-by-doing externality is introduced from nontraditional (manufactured) exports. This externality is assumed to be symmetric, in the sense that while cumulative growth in exports relative to the baseline augments total factor productivity in manufacturing, sluggish export performance reduces it. ${ }^{22}$ The same five basic cases are retained as in table 2 , combined with four variations involving learning by doing and gestation lags, indexed by the letters "a" to "d." Thus, letter "a" always refers to a variation with a learning-by-doing elasticity set at $\psi=0.20$ but no other changes from the assumptions of table 2. Variation " $b$ " is similar, except that this elasticity is set at the very high level of $\psi=0.45$. Variation "c" reverts to setting the learning-by-doing spillover at zero but increases the gestation lag on public investment to three years. Variation " $d$ " combines a learning-by-doing elasticity of 0.2 with the three-year lag.

The first point to note is that simply inserting learning by doing into the unproductive case (experiment 1a) has fairly strong adverse effects. What was a relatively slow deterioration in the original unproductive case is now accelerated. The costs of accepting aid but then wasting it are markedly raised. Turning to the productive cases, two features stand out. The first is that, as the model in section I anticipates, this second spillover pulls in the opposite direction to the infrastructure effect, at least over the horizon of these simulations. Second, however, even at what is arguably a rather high learning-by-doing elasticity of $\psi=0.20$, the "positive" impact flowing from the aid-funded infrastructure investment still dominates. For example, when productivity effects are neutral, the learning-by-doing effect lowers medium-term (10-year) GDP growth only from 7.6 to 7.3 percent and total real income growth from 6.5 to 6.2 percent (experiment $2 \mathrm{a}$ compared with experiment 2). Obviously, manufacturing exports bear most of the cost (falling from a medium-term growth of 8.6 percent to one of 5.1 percent), but this is partly offset by stronger growth in traditional exports.

As experiment $2 \mathrm{~b}$ indicates, however, a substantially larger learning-bydoing elasticity $\psi=0.45$ would inhibit recovery in manufacturing exports (still down by 3.1 percent after 10 years) and knock a further 1 percent off growth in real GDP.

The second reason why the results in table 2 may be seen as painting a relatively positive picture is the assumption that public infrastructure investment in period $t$ augments the public capital stock in $t+1$. Experiments $\mathrm{c}$ and $\mathrm{d}$

22. Since zero total factor productivity growth is assumed in the baseline, this relative decline manifests itself as an (rather unrealistic) absolute decline in total factor productivity. This has no material bearing on the qualitative nature of the results, however. 


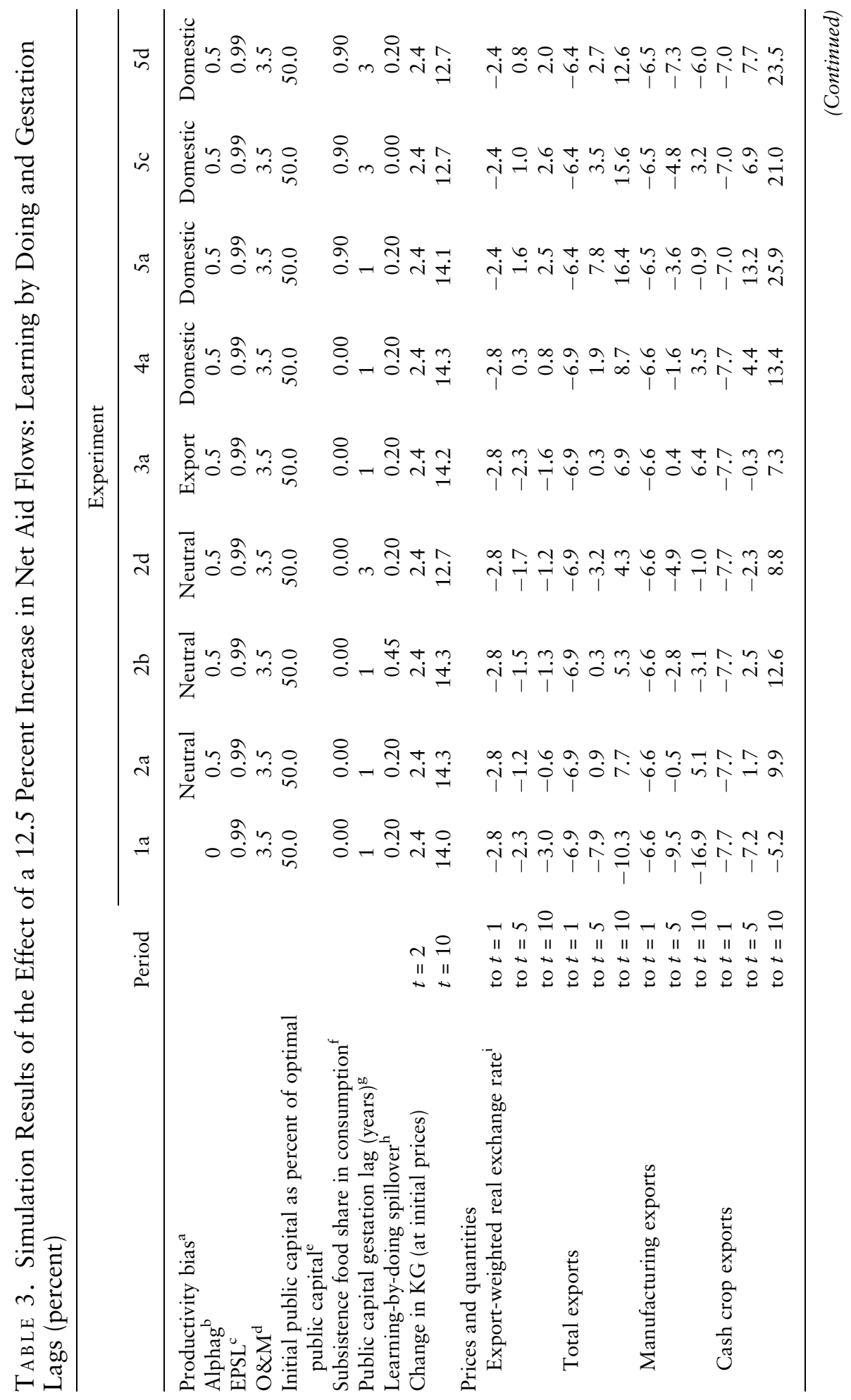




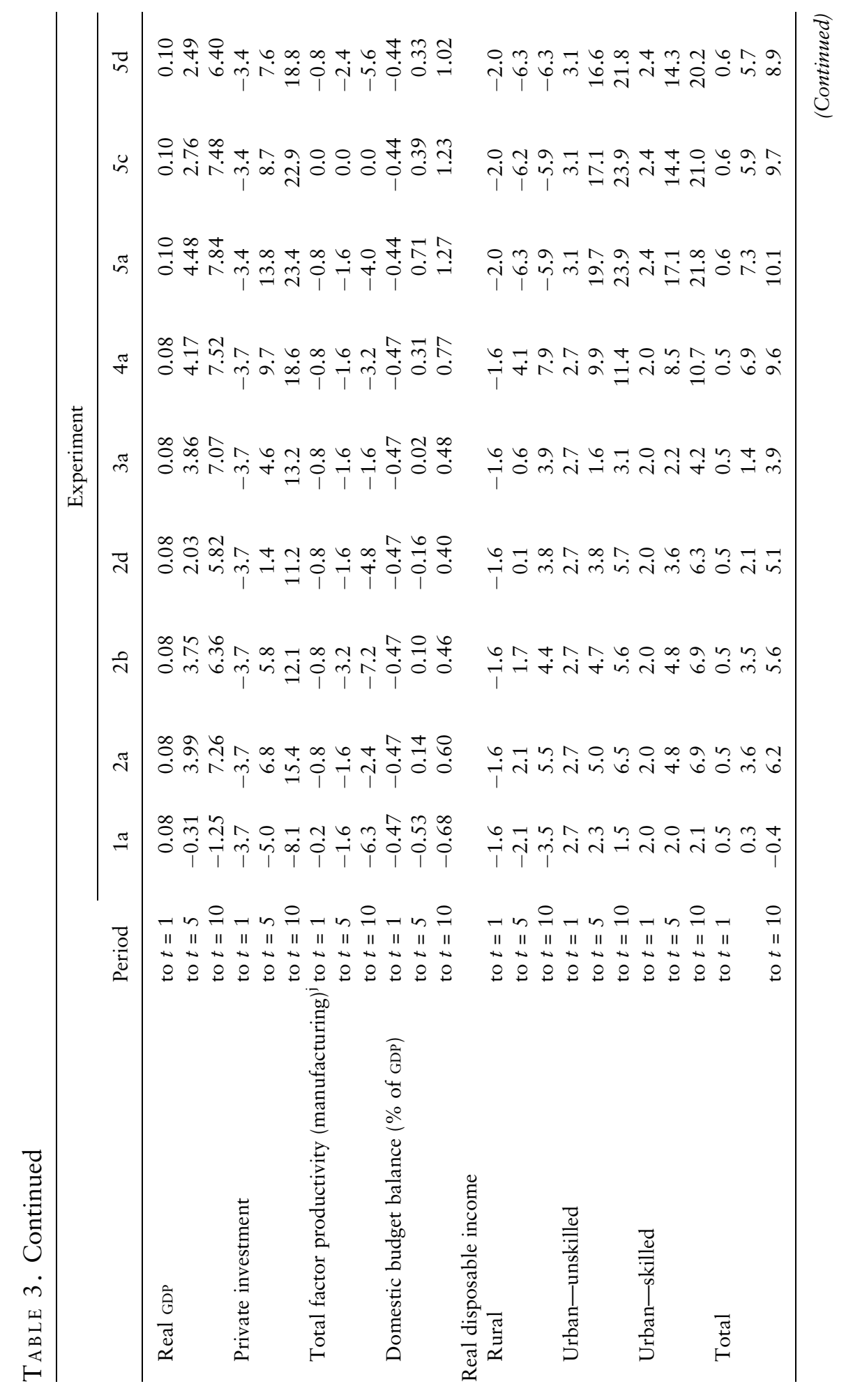




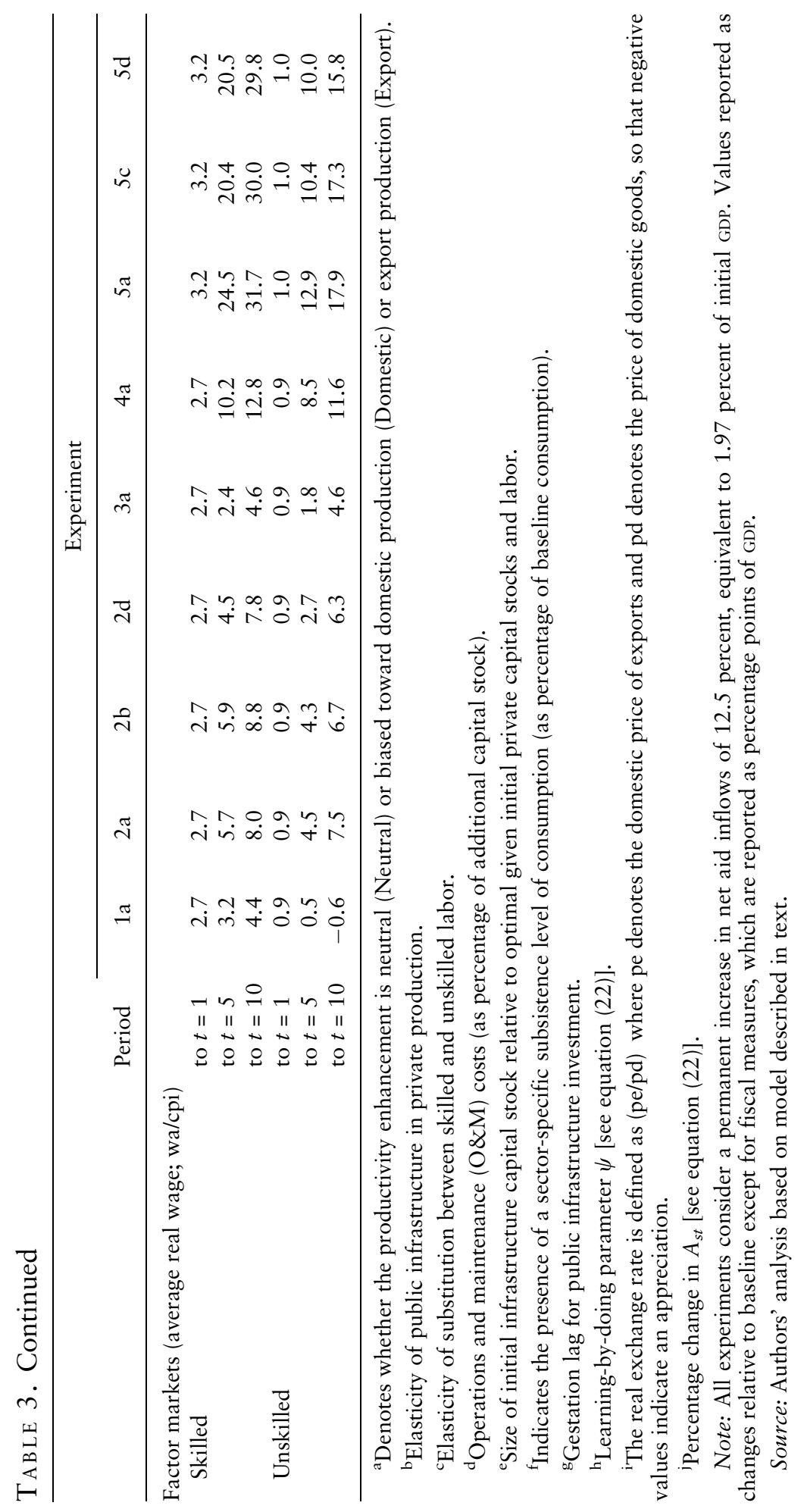


allow public investment in $t$ to augment the capital stock only in $t+3$. This rather naturally elongates the "J-curve" effects seen throughout these simulations for exports and lowers the rate of GDP and real income growth but does not eliminate the recovery in total exports or the growth in income (e.g., in experiment $2 \mathrm{~d}$, the growth in total exports is roughly halved relative to experiment 2).

It is worth highlighting one important feature of the results for all variants of experiment 5: the decline in rural incomes in these experiments is immediate and persistent. In contrast to what is happening elsewhere in the economy, it is the demand effects rather than the supply factors that drive rural incomes in both the short and the medium term. This is seen very clearly from the fact that changes in supply-side factors across all variants of experiment 5 alter the pattern of rural incomes very little indeed.

\section{Sensitivity and Robustness Checks}

The sensitivity of these central results to a battery of robustness checks is discussed in the supplemental appendix S.III. Broadly speaking, these experiments suggest that the qualitative character of the simulations is unchanged by such variations in specification as the effects of altering the elasticity of substitution between skilled and unskilled labor, varying the nontradable intensity of public investment, altering the assumed initial endowment and productivity of public infrastructure capital, changing the assumptions concerning O\&M expenditures, and altering the closure rule.

\section{Summary and Conclusions}

Six key conclusions emerge from the simulations presented in this article. First, when public infrastructure augments the productivity of private factors, and when there is an initial scarcity of public infrastructure, there are potentially large medium-term welfare gains from aid-funded increases in public investment, despite the presence of short-run Dutch disease effects of aid.

Second, the dynamic and distributional consequences of this investment are highly sensitive to the location of productivity effects and the characteristics of demand.

Third, the presence of a domestic bias in the aggregate supply response (experiments 4 and 5) is broadly beneficial to the economy in terms of boosting aggregate growth and investment, welfare, and exports and moderating appreciation of the real exchange rate.

Fourth, across most experiments, particularly when there is a domestic-good bias in the supply response, the rural household does not share proportionately in the aggregate income gains to the economy. In particular, if a domestic bias in productivity is combined with a high subsistence requirement in food (experiment 5), the economy as a whole enjoys a large supply response that dominates 
the other cases, but at the cost of falling rural incomes and a sharp worsening in the income distribution.

Fifth, there are potentially substantial payoffs through an improved fiscal balance and increased private investment, regardless of the presence or absence of bias (experiments 2-5).

Lastly, the results suggest that while it is certainly possible to identify configurations of parameters such that aid-funded increases in public investment leave the economy worse off than without aid, this requires very low values for the productivity of public expenditure in circumstances where the public capital stock is already very close to its optimum and high values of the learning-bydoing externality.

These conclusions must, of course, be qualified by a number of caveats. First, the modeling of the labor market here has been vestigial. In particular, it permits no migration from rural to urban sectors so that improved productivity in traditional agriculture becomes problematic, condemning rural households to declining real incomes rather than stimulating migration into the urban tradable sectors. Similarly, there is no scope in the model for rural households to shift to tradable forms of production. Second, the model does not allow for any form of human capital formation. Future work will extend the model to address both these shortcomings.

However, one general conclusion can be drawn from the analysis with considerable confidence: serious analysis of the impact of aid must pay close attention to supply-side issues, which are likely to be specific to the uses to which aid is put. It should not seem paradoxical that a proper assessment of the macroeconomic impact of aid depends closely on the underlying microeconomics of the associated public expenditures it finances.

\section{REFERENCES}

Adam, C. S., and S. O’Connell. 1999. "Aid, Taxation, and Development in Sub-Saharan Africa.” Economics and Politics 11(3):225-53.

- 2004. "Aid Versus Trade Revisited: Donor and Recipient Policies in the Presence of Learning-byDoing.” Economic Journal 114(492):150-73.

Agénor, P.-R., N. Bayraktar, and K. El Aynaoui. 2005. "Roads Out of Poverty? Assessing the Links Between Aid, Public Investment, Growth, and Poverty Reduction.” Policy Research Paper 3490. World Bank, Washington, D.C.

Commission for Africa. 2005. Our Common Interest. London.

Devarajan, S., J. D. Lewis, and S. Robinson. 1993. "External Shocks, Purchasing Power Parity, and the Equilibrium Real Exchange Rate.” World Bank Economic Review 7(1):45-63.

Elbadawi, I. 1999. "External Aid: Help or Hindrance to Export Orientation in Africa?” Journal of African Economies 8(4):578-616.

Gylfason, T., T. T. Herbertsson, and G. Zoega. 1997. “A Mixed Blessing: Natural Resources and Economic Growth.” CEPR Discussion Paper 1668. Centre for Economic Policy Research, London.

Hood, R., D. Husband, and F. Yu. 2002. "Recurrent Expenditure Requirements of Capital Projects." Policy Research Working Paper 2938. World Bank, Washington, D.C. 
Hulten, C. 1996. "Infrastructure Capital and Economic Growth: How Well You Use It May Be More Important than How Much You Have.” NBER Working Paper 5847. National Bureau of Economic Research, Cambridge, Mass.

Matsuyama, K. 1992. "Agricultural Productivity, Comparative Advantage, and Economic Growth." Journal of Economic Theory 58(2):317-34.

Rajan, R., and A. Subramanian. 2005. "What Undermines Aid's Impact on Growth?” IMF Working Paper 05/126. International Monetary Fund, Washington, D.C.

Sachs, J. D., and A. M. Warner. 1995. "Natural Resource Abundance and Economic Growth.” NBER Working Paper 5398. National Bureau of Economic Research, Cambridge, Mass.

Svensson, J. 2000. "Foreign Aid and Rent Seeking." Journal of International Economics 51(2):437-61.

Torvik, R. 2001. "Learning by Doing and the Dutch Disease." European Economic Review 45(2): 285-306.

United Nations Millennium Project. 2005. Investing in Development: A Practical Plan to Achieve the Millennium Development Goals. New York.

Van Wijnbergen, S. J. 1984. “The 'Dutch Disease': A Disease after All?” Economic Journal 94(373):41-55. 